\title{
2014s-19
}

\section{Insensitivity to Prices in a Dictator Game}

\author{
Jim Engle-Warnick, Natalia Mishagina
}

\begin{tabular}{c}
\hline Série Scientifique \\
Scientific Series
\end{tabular}

\section{Montréal \\ Février 2014/February 2014}

(C) 2014 Jim Engle-Warnick, Natalia Mishagina. Tous droits réservés. All rights reserved. Reproduction partielle permise avec citation du document source, incluant la notice $($ ).

Short sections may be quoted without explicit permission, if full credit, including @ notice, is given to the source.
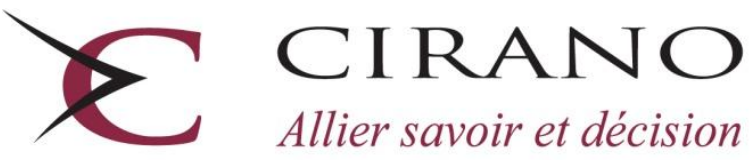

Allier savoir et décision

Centre interuniversitaire de recherche en analyse des organisations 


\section{CIRANO}

Le CIRANO est un organisme sans but lucratif constitué en vertu de la Loi des compagnies du Québec. Le financement de son infrastructure et de ses activités de recherche provient des cotisations de ses organisations-membres, d'une subvention d'infrastructure du Ministère de l'Enseignement supérieur, de la Recherche, de la Science et de la Technologie, de même que des subventions et mandats obtenus par ses équipes de recherche.

CIRANO is a private non-profit organization incorporated under the Québec Companies Act. Its infrastructure and research activities are funded through fees paid by member organizations, an infrastructure grant from the Ministère de l'Enseignement supérieur, de la Recherche, de la Science et de la Technologie, and grants and research mandates obtained by its research teams.

\section{Les partenaires du CIRANO}

\section{Partenaire majeur}

Ministère de l'Enseignement supérieur, de la Recherche, de la Science et de la Technologie

\section{Partenaires corporatifs}

Autorité des marchés financiers

Banque de développement du Canada

Banque du Canada

Banque Laurentienne du Canada

Banque Nationale du Canada

Banque Scotia

Bell Canada

BMO Groupe financier

Caisse de dépôt et placement du Québec

Fédération des caisses Desjardins du Québec

Financière Sun Life, Québec

\section{Gaz Métro}

Hydro-Québec

Industrie Canada

Investissements PSP

Ministère des Finances et de l'Économie

Power Corporation du Canada

Rio Tinto Alcan

Transat A.T.

Ville de Montréal

\section{Partenaires universitaires}

École Polytechnique de Montréal

École de technologie supérieure (ÉTS)

HEC Montréal

Institut national de la recherche scientifique (INRS)

McGill University

Université Concordia

Université de Montréal

Université de Sherbrooke

Université du Québec

Université du Québec à Montréal

Université Laval

Le CIRANO collabore avec de nombreux centres et chaires de recherche universitaires dont on peut consulter la liste sur son site web.

Les cahiers de la série scientifique (CS) visent à rendre accessibles des résultats de recherche effectuée au CIRANO afin de susciter échanges et commentaires. Ces cahiers sont écrits dans le style des publications scientifiques. Les idées et les opinions émises sont sous l'unique responsabilité des auteurs et ne représentent pas nécessairement les positions du CIRANO ou de ses partenaires.

This paper presents research carried out at CIRANO and aims at encouraging discussion and comment. The observations and viewpoints expressed are the sole responsibility of the authors. They do not necessarily represent positions of CIRANO or its partners. 


\title{
Insensitivity to Prices in a Dictator Game*
}

\author{
Jim Engle-Warnick ${ }^{\dagger}$, Natalia Mishagina
}

\section{Résumé/abstract}

We show that violations of demand theory are more numerous than previously reported in experimental two-player dictator games. We introduce a "weighted price" function that shows that violations of revealed preference can be interpreted as the dictator's insensitivity to the price of the dictator's allocation relative to the recipient's allocation. Our paper is the first to rationalize violations of demand theory in dictator games by examining the relationship between violations of GARP and prices. We suggest that weighted prices, and not only preferences, may be a component of decision making in dictator games.

Mots clés/Keywords : Dictator game, WARP, revealed preference.

Codes JEL : C90.

\footnotetext{
${ }^{*}$ We acknowledge the Social Science and Humanities Research Council for funding.

Corresponding author. CIRANO and McGill University, jim.engle-warnick@mcgill.ca

${ }^{\sharp}$ CIRANO.
} 


\section{Introduction}

Revealed preference theory is one of the most fundamental concepts in economic theory. If choices conform to revealed preference theory, then a well-behaved utility function can rationalize them. The importance of revealed preference has led to a vast empirical literature that seeks to devise new methods, or to use better data sets, to more precisely characterize the number and severity of violations of the theory, as well as to better apply it (see Andreoni et al., 2013 and the references therein).

At the same time, a large experimental literature has developed testing revealed preference theory with consumer goods. Because there are so many unobservable aspects to consumer choice, the control of the laboratory environment is ideal for constructing precise tests of revealed preference theory. For example, Battalio et al. (1973) conducted a landmark study of revealed preference using a token economy. Other studies have sought to address specific issues such as the controlling for types of consumer goods (Sippel, 1997), the subject populations (Mattei, 2000; Harbaugh et al., 2001; Burghart st al., 2013), or assumptions on preferences (Cox, 1997).

Revealed preference has also been used to experimentally study rationality of behavior where the good is an allocation of a surplus between two people. These allocations are typically studied using dictator games (Forsythe et al., 1994). In these games, a dictator simply determines a split of an endowment with a recipient. Andreoni and Miller (2002) were the first to vary the price of allocating money to the dictator relative to the price of allocating money to the recipient, and observe resulting violations of the General Axiom of Revealed Preference (GARP). They find that $10 \%$ of their dictator game subjects violate GARP with at least one combination of their choices. ${ }^{1}$ Since the violations are not particularly numerous or severe, the question has been how to treat the minor violations when devising algorithms

\footnotetext{
${ }^{1}$ Fisman et al. (2007) find a greater number of violations, but their experimental design contained non-linear budget constraints that may not be directly comparable to the design of Andreoni and Miller (2002).
} 
to infer utility functions from choice data sets.

What if the violations of GARP were actually not so minor? Such a finding would raise new questions, since significant violations of GARP would preclude the rationalizability of the data. It is possible that the relatively low proportion of observed violations could be due in part to experimental design. Specifically, in past experimental studies, the relative price of allocating money to the dictator compared with the responder has not been extreme (Andreoni et al., 2013). For example, the maximum relative price ratio of money allocated to the dictator to money allocated to the responder happens to be $4-1$ in past studies (e.g., Andreoni and Miller, 2002).

Imagine doubling this price ratio to $8-1$, with a total budget of $\$ 16$ in both cases. In the case of the 4-1 price ratio, that is, when the price of the dictator's allocation is 4 and the price of the responder's allocation is 1 , with a total budget of $\$ 16$ the dictator could allocate all $\$ 16$ to the responder (if she maximizes the sum of the payoffs) or $\$ 4$ to herself (if she is completely self-interested). However, in the case of the dictator price of 8 , these amounts are $\$ 16$ to the responder and $\$ 2$ to the dictator, respectively. Now imagine a dictator whose preference is to evenly split the budget with the responder. With a dictator price of 4 , each player would receive $\$ 3.20$, and with a dictator price of 8 , each player would receive a little under $\$ 2$.

Our conjecture is that a consistent application of any preference becomes difficult when the resulting allocation tends toward an extreme, which occurs as relative prices increase. It seems possible that this characteristic of the game may cause decision makers to fail to adjust decisions enough relative to large changes in prices to be consistent with demand theory. In our experiment we explore this possibility by varying the relative prices precisely in this way, and we find significantly more violations of GARP than have been found in the past: roughly $70 \%$ of our subjects violate GARP. These violations are also more serious than those previously found. 
The standard method of measuring the magnitude of a violation, the Critical Cost Efficiency Index (CCEI), is due to Afriat $(1967,1972)$ and Varian (1991). Intuitively, it measures the amount of the budget that is wasted by an inconsistent decision by shifting budgets inward until the choice data are rationalizable. By this measure, we find substantially larger budget wasting in our data than in past studies. However, it is not clear why facing more extreme prices would result in decision makers wasting more of their budget, even if it results in more violations of GARP. The problem is that with the current measure of violation magnitude, that is the CCEI, this is the only interpretation existing.

In this paper we consider the role of prices in violations of GARP by introducing a new method to measure the magnitude of GARP violations in demand data. We simply apply income-compensated price changes to the budgets that contain a GARP violation. With an algorithm we determine a set of prices that make the choice data rationalizable. We then construct a price function that maps the income-compensated prices, which we call the dictator's weighted prices, to the actual experimental prices. ${ }^{2}$ We then find that after accounting for the weighted prices, the distribution of CCEI among our subjects is closer to that in past experiments. This suggests that extreme pricing is behind our experimental results, and that our price weighting function usefully adjusts the data so that it can be rationalized by a standard utility function.

Our analysis of the weighted price function shows that the dictators systematically overweigh low dictator prices and underweigh high dictator prices. The effect is as if prices at each extreme are being pushed toward a price in the middle. We call this behavior price insensitivity. ${ }^{3}$ We also find an overall tendency for the weighted dictator price to be always lower than the actual price. The effect is as if it is less expensive to allocate to the dictator than it actually is. We call this own-price discounting. ${ }^{4}$ We show that the distribution

\footnotetext{
${ }^{2}$ The price weighting function is identical to the probability weighting function of Prelec (1998), experimentally applied by Abdellaoui et al. (2011) to ambiguity source functions.

3 Price insensitivity is analogous to likelihood insensitivity in probability weighting.

${ }^{4}$ Own-price discounting is analogous to pessimism (with regard to the chance of winning the best outcome
} 
of parameter estimates of our model for subjects who commit violations is skewed toward both price insensitivity and own-price discounting, and we present individual examples of the heterogeneity with regard to these two characteristics of the weighted prices in our data.

\section{Experimental Design}

\subsection{Violations of Demand Theory}

We briefly review the core axioms of revealed preference, which are based on Afriat (1967), Houthakker (1950), Samuelson (1938), and Varian (1982, 1983, and 1991). For a vector of prices $p$ and consumption bundles $x, x^{t}$ is preferred to $x^{s}$ if $x^{s}$ is affordable when $x^{t}$ is chosen (i.e., $\left.p^{t} x^{t} \geq p^{t} x^{s}\right)$. Then $x^{t}$ is directly revealed preferred to $x^{s}\left(x^{t} R^{d} x^{s}\right)$ if $p^{t} x^{t} \geq p^{t} x^{s}$. Bundle $x^{t}$ is strictly revealed preferred if the inequality is strict. Taking into account transitivity of preferences, $x^{t}$ is revealed preferred to $x^{s}\left(x^{t} R x^{s}\right)$ if there is a chain of directly preferred bundles between $x^{t}$ and $x^{s}$. The following three definitions summarize the core axioms.

Definition 1. Weak Axiom of Revealed Preference (WARP): If $x^{t}$ is directly revealed preferred to $x^{s}$, then $x^{s}$ is not directly revealed preferred to $x^{t}$.

Definition 2. General Axiom of Revealed Preference (GARP): If $x^{t}$ is revealed preferred to $x^{s}$, then $x^{s}$ is not strictly directly revealed preferred to $x^{t}$.

\subsubsection{Detecting Violations}

WARP is the fundamental test of rationality in dictator game choice data: if a pair of choices satisfy WARP then they can be rationalized by a utility function. Afriat's (1967) theorem extends the rationalizability result to the case with more than two goods using GARP, which is testable since GARP can be thought of as WARP with transitivity. Afriat's theorem sets in a gamble) in probability weighting. 
the strategy for analyzing choice data. First, one designs a set of choices in which budget lines cross each other in an area where choices are likely. Second, one locates the violations of WARP among all pairs of choices. Third, one locates the violations of GARP by finding the transitive chains in the WARP violations.

We identify violations of WARP by creating a $k \times k$ matrix $M$ for each subject, where $k$ is the number of budgets faced by each subject. An entry $(t, s)$ of this matrix, $M_{t s}$, equals 1 if $p^{t} x^{t} \geq p^{t} x^{s}$ and 0 otherwise. A pair of choices $\left\{x_{t}, x_{s}\right\}$ violates WARP if $M_{t s}=1$ and $M_{s t}=1$. We then can identify violations of GARP by computing the transitive closure of matrix $M$, denoted $M T$ (Varian, 1982). This transitive closure matrix identifies all cases when a bundle is revealed preferred to another through a chain of bundle choices (e.g., $x^{i} R^{d} x^{k}, x^{k} R^{d} x^{m}, \ldots, x^{n} R^{d} x^{j}$ results in $M T_{i j}=1$, and 0 otherwise). Then a pair of choices $x^{i}, x^{j}$ violates GARP if $M T_{i j}=1$ and $x^{j} p^{j}>x^{i} p^{j}$.

\subsubsection{Measuring the Severity of Violations}

A traditional measure of severity of violations is the Afriat's Critical Cost Efficiency Index (CCEI). The CCEI indicates by what fraction budgets must be be relaxed to eliminate all violations. The idea behind the CCEI is that when a revealed preference violation occurs, only a certain share of a budget was spent efficiently, and the rest was "wasted". Therefore, the removal of the wasted share of a budget rationalizes the pair of choices that constitute this violation (Afriat 1967, 1972; Varian 1990, 1991). The index ranges between 0 and 1. An index of 1 implies no GARP violations. The lower the index the more severe the violations, since budgets have to be relaxed to a larger extent to eliminate more severe GARP violations. Andreoni et al. (2013) provide a useful formal definition of the CCEI. 
Figure 1: Average Choices in the Dictator Game

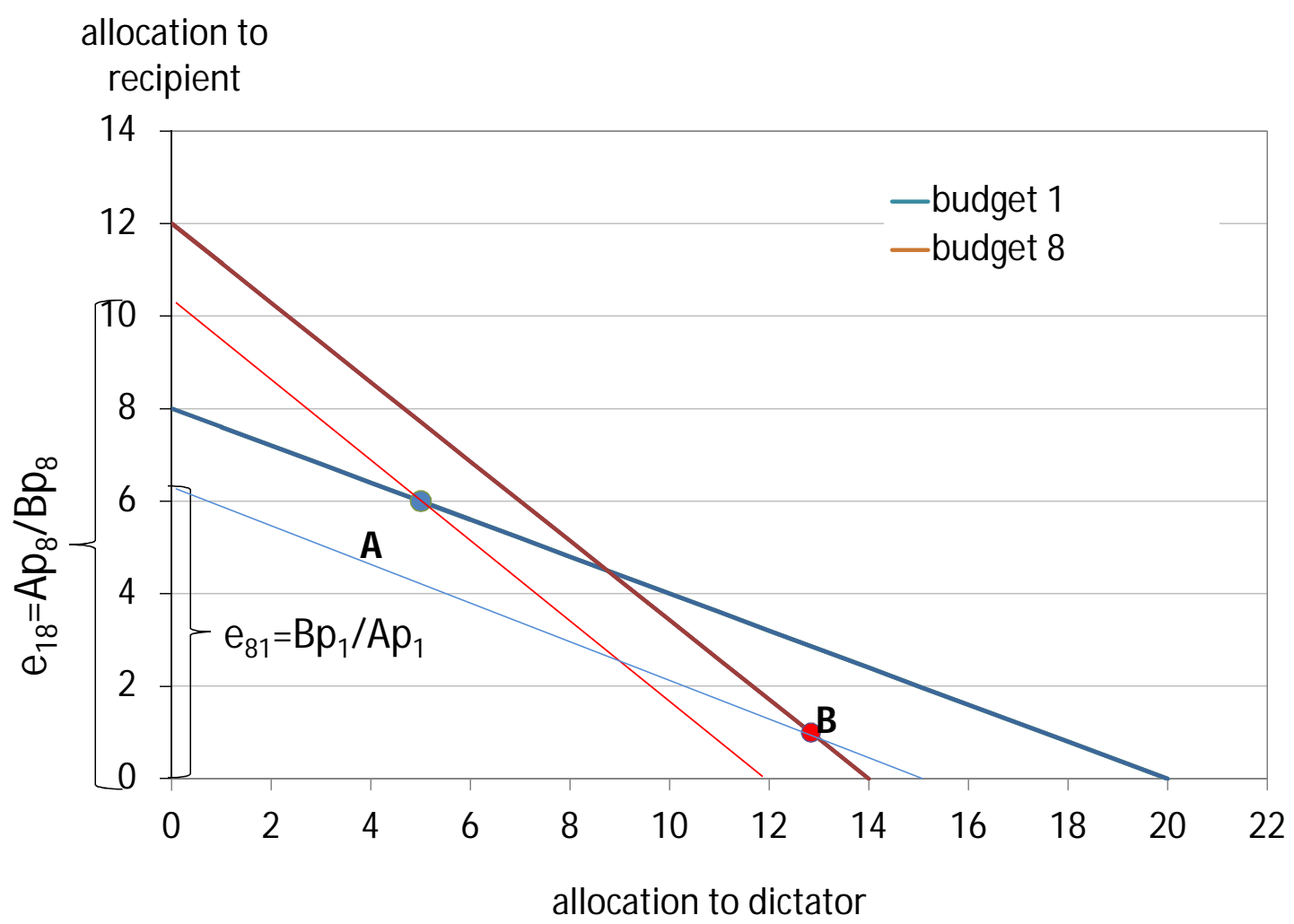

\subsubsection{An Example of a Violation and Its Severity}

Consider the actual choices of a particular subject in our data facing two budgets: budget 1 (blue line) and budget 8 (red line) illustrated in Figure 1. This pair of choices represents a violation of direct revealed preference because the choice at budget 1 (bundle $A$ ) was affordable at budget 8 when bundle $B$ was chosen, and vice versa. These choices also have an intuitive interpretation in terms of the dictator game. The relative price of keeping at budget 1 was lower than that at budget 8 , and yet the subject chose to give less to herself at budget 1 than at budget 8 . 
Using the same Figure 1, we illustrate CCEI for the WARP violation presented on the figure. When bundle $A$ was chosen at budget 1 , bundle $B$ was affordable at a total cost of $B p_{1}$, which amounts to a share of budget 1 equal $e_{81}=B p_{1} / A p_{1}$. That is, by choosing bundle $B$ the subject would have wasted $1-e_{81}$ of budget 1 . Similarly, by choosing bundle $A$ when facing budget 8 , the subject would have spent a share of budget 8 equal $e_{18}=A p_{8} / B p_{8}$ and, therefore, wasted a share of budget equal $1-e_{18}$. The smaller of the two wasted budget shares is $1-e_{18}$, which occurred when bundle $B$ was chosen at budget 8 . Varian (1991) suggests that this particular violation can be eliminated if budget 8 is reduced by $1-e_{18}$ (i.e., the wasted budget share). This way, $e_{18}$ indicates the efficiency of this particular choice of the subject.

The reason behind applying a perturbation to the budget where the smallest waste occurred is that small violations are more likely than large violations. Varian then goes on to define the choice made at the budget with the smallest correction as a "mistake" (budget 8), whereas the choice at budget 1 he defines as the one that most likely reveals the true

preference (because otherwise, the waste would have been larger). We will use these terms in what follows.

Afriat's CCEI thus views violations of demand theory through the lens of budget wasting. Given a pair of choices that violate WARP, one can always reduce one budget or the other until the violation is removed. Since the new budget is smaller, the decision wasted the difference between the original budget and the adjusted budget.

\subsection{Violations of Demand Theory Through the Lens of Prices}

\subsubsection{Rationalizing Violations with a Price Adjustment}

In this paper we suggest that violations of demand theory are more naturally viewed through a lens that includes both budget and prices, rather than budget alone as with the CCEI. Here, we introduce a new thought experiment, illustrated in Figure 2, which uses the same set of 
budgets and choices as Figure 1. To rationalize this choice and remove the violation, imagine reducing the dictator's own price just enough to make the new budget line parallel to a line through the two choices on the figure, and only then removing some money from the budget to make the original allocation just affordable. As before, we apply these modifications to budget 8 , the one where the smaller share of budget was wasted. The intuition behind this modification is that for the choice to be rational, the subject acted as if $p_{8}$ was actually more favourable to keep money than it actually was (hence, we pivot the budget), and then we must take away a portion of the budget to remove the violation by shifting it in.

The resulting budget line is the red dashed line that goes through both choices $A$ and $B$. Now, an $\epsilon$-perturbation of the price completely removes the violation by making bundle $A$ unaffordable when $B$ was chosen, eliminating the revealed preference violation. Now had budget 8 had actually been the red dashed line, rather than the red solid line, the two choices would not have violated WARP. The proposed income-compensated price adjustment makes the two choices rationalizable. Therefore, our budget adjustment has a behavioral interpretation: rather than "wasting" budget as with the CCEI, the subjects who violate WARP behave as if they misinterpreted the price of allocating money to themselves either by overweighing or by underweighing it. Subjects responded to a weighted price, rather than the objective price presented to them. In what follows, we refer to this procedure as the income-compensated price adjustment algorithm (ICPA).

\subsubsection{Measuring Severity with ICPA-Augmented CCEI}

Our first new algorithm, the ICPA-Augmented CCEI algorithm, makes the smallest incomecompensated adjustments to prices before computing the CCEI. It first applies the ICPA to budgets where mistakes were made to reduce the number of violations, and then computes the implied budget wasting that eliminates all remaining violations. The purpose of this algorithm is to investigate to which extent price adjustments render the data more or less 
Figure 2: Income-compensated prices to eliminate a WARP violation

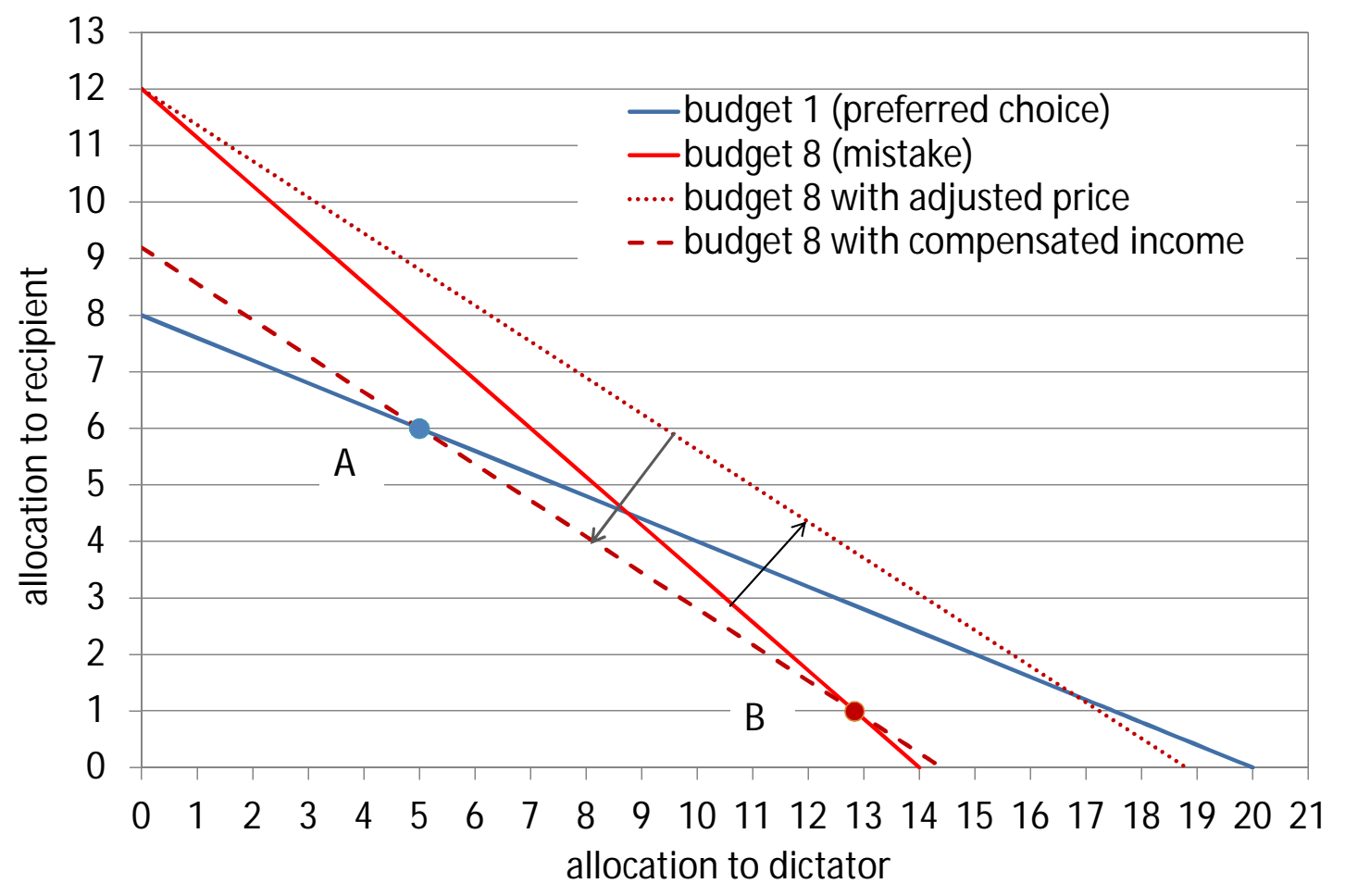


compatible with past empirical studies. Recall that our prices varied more widely than price in past experiments. The question is to what extent this feature of the design can explain the difference between the results.

The algorithm proceeds as follows. We first determine all pairwise violations, and in each pair we determine which budget has to be adjusted to eliminate that particular pair of violations. Since a particular budget may be involved in more than one pair of violations, thus having to be adjusted more than once, we perform the smallest adjustment to both the price and the income of each budget identified to be modified at the previous step. ${ }^{5}$ To eliminate all remaining violations, we apply the Afriat's procedure of eliminating budget wasting until all violations in the data are rationalized. The algorithm can be presented as the following steps:

1. Identify all pairs of budgets that violate WARP.

2. For each pair of WARP violations, identify choices that are mistakes.

3. Find and apply the smallest adjustment using the ICPA to the dictator's own price in each budget where a mistake was made.

4. Apply the Afriat's procedure to the set of new budgets obtained in Step 3 until all violations are eliminated.

\subsubsection{Rationalizing Data with ICPA}

Our second new algorithm, the iterative ICPA, determines the set of budgets that render the data rationalizable through repeated application of price adjustments alone until no violations remain (i.e., without applying budget wasting). It simply repeats steps from 1 to 3 of the ICPA-augmented CCEI algorithm described in section 2.2.2 until all violations are eliminated. When it terminates, we are left with a set of budgets with rationalizable choices and with a new set of prices that should shed new light on decision-making in the game:

\footnotetext{
${ }^{5}$ Note, that a modification of one budget will eliminate a violation in a particular pair of budgets, but not necessarily in all pairs involving the modified budget. Moreover, additional violations may be created, which would not have occurred had a budget not been modified.
} 
1. Identify all pairs of budgets that violate WARP.

2. For each pair of WARP violations, identify choices that are mistakes.

3. Find and apply the smallest adjustment using the ICPA to the dictator's own price in each budget where a mistake was made.

4. Stop if all violations are eliminated, if not return to Step 1.

\section{$3 \quad$ Experimental Procedures}

We presented subjects in a two-player dictator game with 20 budget constraints of the form $p x_{d}+x_{r}=m$, where $x_{d}$ is the amount of money that goes to the dictator, $x_{r}$ is the amount that goes to the recipient, $p$ is the relative price of keeping money by the dictator (i.e., the recipient price is normalized to 1 ), and $m$ is the normalized budget. We randomly drew each of the 20 budget constraints as follows. We allowed all budget constraints where the maximum amount either subject could earn if taking (or receiving) the entire pie was an even amount between $\$ 2$ and $\$ 20$. We then drew an equal number of budgets such that it was relatively expensive or inexpensive to keep the money by the dictator (i.e., such that the relative price $p$ was above or below 1). Figure 3 shows the budget constraints used in the experiment.

All subjects made decisions as if they were dictators, but subjects were informed that only one subject in each pair would be randomly chosen to actually be the dictator. The subject who was not chosen to be the dictator was effectively the recipient in the resulting dictator game. Thus, subjects played a dictator game using the strategy method, where they reported what they would do in every case if they were to be chosen to be the dictator. This method eliminates allocations that are chosen to distribute payments across both roles.

Subjects entered their decisions into a computer interface, which displayed the current budget. The screen contained a calculator, which would compute the amount the dictator would earn for any allocation for the recipient. Subjects made their final decisions in a 
different box on the screen and pressed an OK button to confirm the choice. The experiment was programmed and conducted with the software z-Tree (Fischbacher, 2007).

There were 156 subjects in our experiment. Half of them were women (51\%), 22.5 years old on average, and slightly less than half of them have previously participated in similar experiments (44\%). The subjects were paid for one randomly chosen decision in the session, and earned on average $\$ 26$ plus a show-up fee of $\$ 10 .^{6}$

\section{Experimental Results}

\subsection{Average Allocations}

Figure 3 presents the budget constraints and the average choice across all participants for each constraint. The legend in the top right corner of the figure indicates the budget $(m)$ and the dictator price $(p)$ for each of the 20 budget constraints. In the figure, the dictator's own allocation of money is presented on the $x$-axis, and the recipient's allocation is located on the $y$-axis. The largest possible allocation for either player for any budget constraint is $\$ 20$, and the smallest is $\$ 2$. For example, budget constraint 17 illustrates an extreme dictator price of 8 . This budget line intersects the $x$-axis at $\$ 2$ and the $y$-axis at $\$ 16$. Budget constraint 13 with a dictator price of 1 intersects both axes at $\$ 18$. Among other items, the figure shows the diversity of budget constraints in the experimental design. Figure 3 reveals that all but two average allocations occur well inside the budget constraints. The two that occur relatively close to a corner do so in favor of the dictator: budget sets 7 and 20 where dictator prices are 0.148 and 0.1 , respectively (i.e., where it is inexpensive for the dictator to give to herself). Notice the overall apparent bias toward allocation to self: for the budget constraints

\footnotetext{
${ }^{6}$ After the dictator game, subjects made decisions in a brief sequence of two-player games. The twoplayer games were not described in the instructions for the dictator games, they were not expected at the time that the dictator decisions were made, and thus had no effect on decisions in them. The purpose of the two-player games was to predict behaviour using preferences estimated from choices in the dictator games, a task we leave for future work.
} 
Figure 3: Average Choices in the Dictator Game

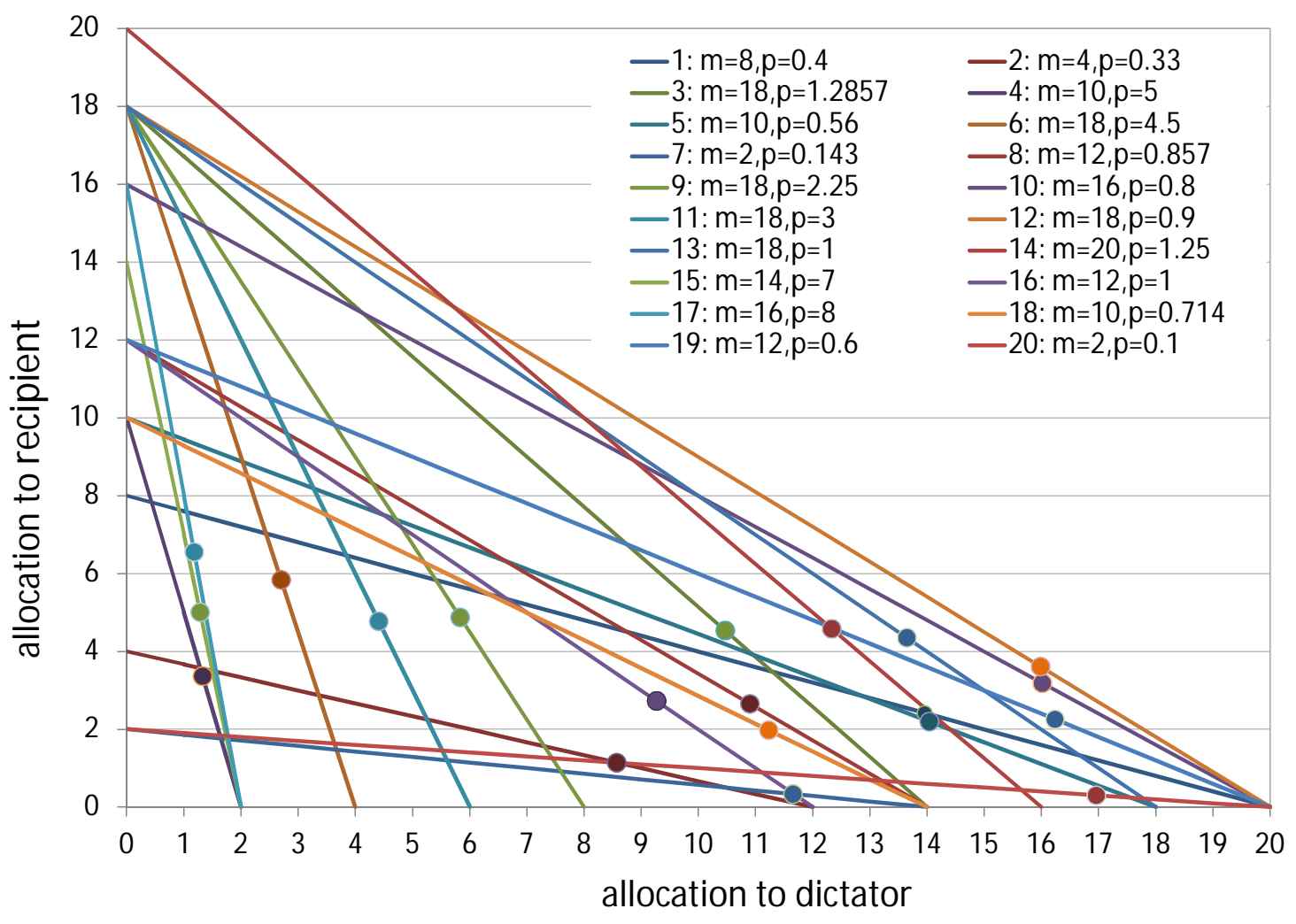


where the dictator price is 1 or less, all of the average choices allocate at least $\$ 8.50$ to the dictator. In all of these cases, dictators allocate more to the dictator than to the recipient.

By contrast, note budget constraints 4,15 , and 17, all of which intersect the $x$-axis at $\$ 2$, and all of which make it expensive to allocate money to the dictator. In these cases, the average decision moves closer to an even split. In fact, all average allocations of less than $\$ 6$ to the dictator share a similar characteristic: splits are more even when the relative price of keeping is high than when it is low. Thus, overall the price has a predictable effect on allocations, with a tendency for dictators to allocate more to self. All of these observations are consistent with the fact that the average percentage allocation to dictators across all games was $74.75 \%$, which is very similar to the share of $73 \%$ found in Andreoni and Miller (2002). This figure suggests a bias in dictators towards allocating money to themselves, but by itself it cannot reveal consistency of individual behavior.

\subsection{Rationality of Choices}

Out of 156 subjects in our experiment, 109 subjects (70\%) have at least one violation of WARP. ${ }^{7}$ In total, these 109 subjects have 436 WARP violations. Figure 4 is a histogram of the number of WARP violations per subject conditional on having made a violation. Twentynine subjects (almost 30\%) violate WARP once. Sixty-seven subjects violate WARP one, two, or three times. The vast majority of subjects who violate WARP do so 10 times or less, and only four subjects do so more often, the maximum being 18 times. Next, we proceeded to identify GARP violations for these 109 subjects, which in total amount to 2,286 violations. ${ }^{8}$

Since the main interest of the paper is the relationship between the prices and violations, we next discuss the distribution of WARP and GARP violations for different budgets. Figure 5 presents violations of revealed preference by budget. The horizontal axis contains

\footnotetext{
7 The number and the severity of violations did not significantly vary with subjects' age, gender, or previous experience with these kind of experiments.

8 The Bronar's test results in the power of 0.985 (i.e., the probability that a random subject has violations).
} 
Figure 4: Distribution of WARP violations per subject

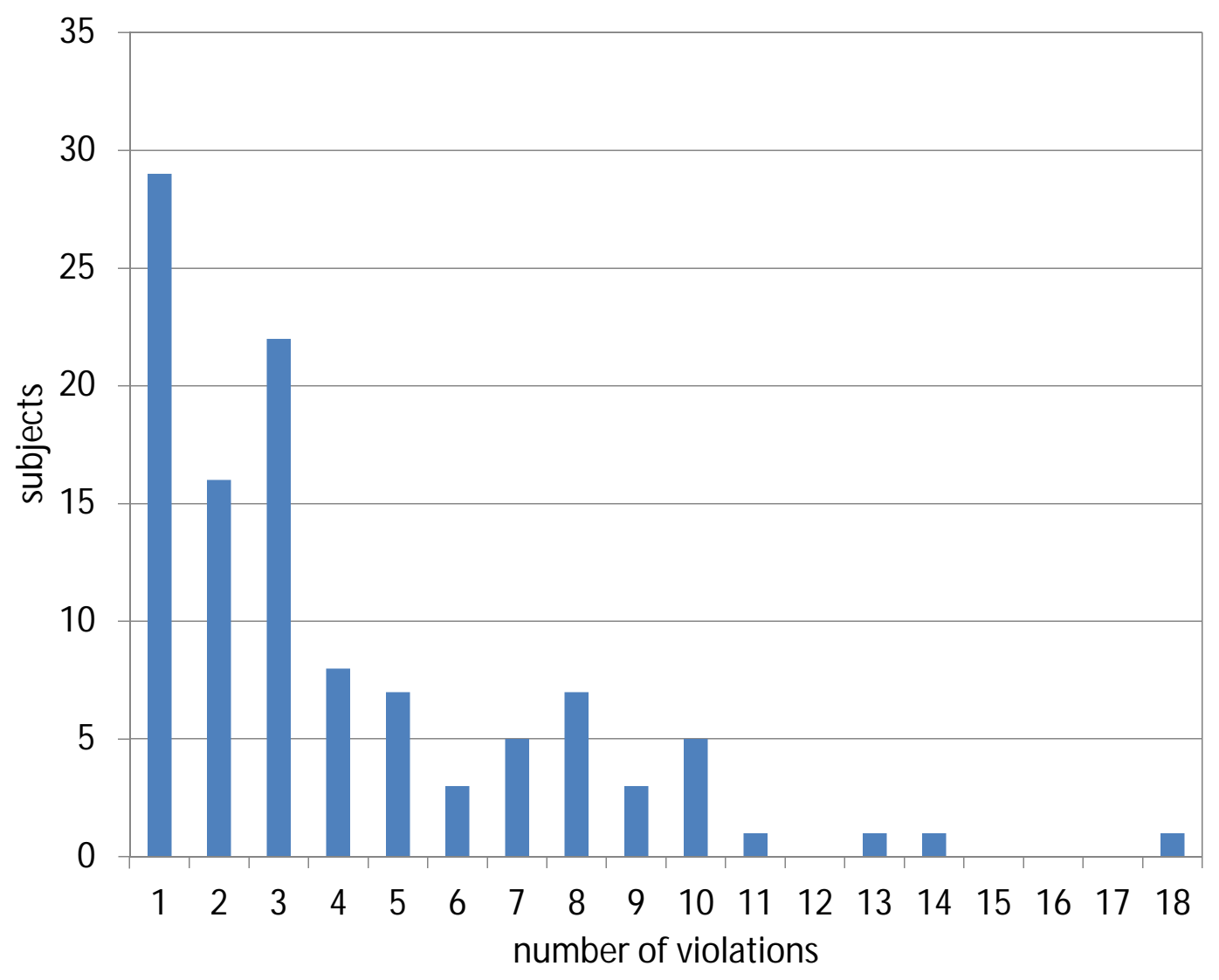


Figure 5: Distribution of WARP and GARP violations, by relative price

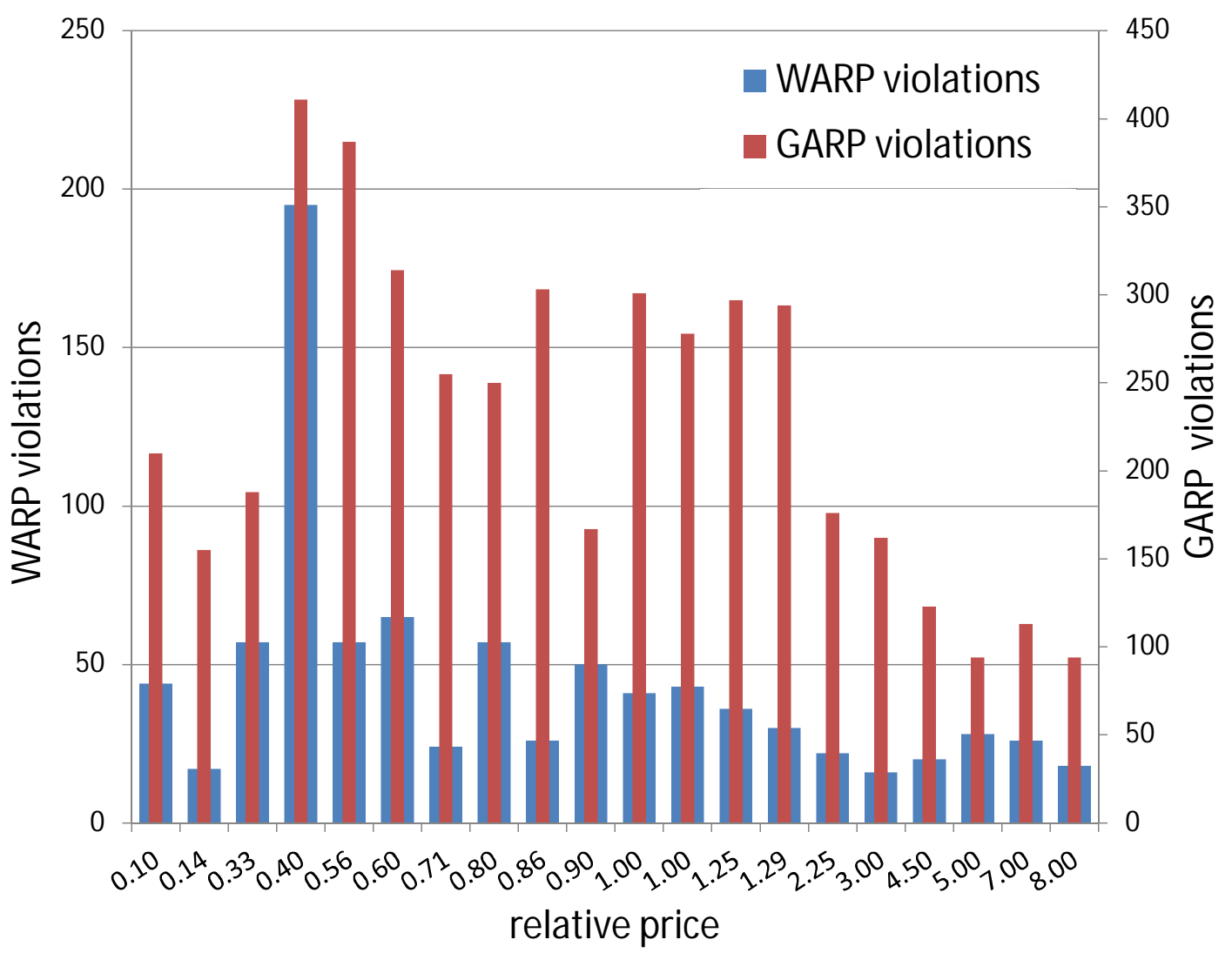

experimental budgets sorted by the dictator price in ascending order and labeled accordingly, and the vertical axes represent the number of violations in the data. The left vertical axis shows the number of violations of WARP, and the right axis shows the number of violations of GARP. Note that violations are presented twice in this figure, once for each of the two budget constraints involved in a pair of budgets constituting one violations. The wide bars represent WARP violations and the narrow bars represent GARP violations.

The maximum number of violations occur at a dictator price of 0.40 : there are nearly 200 WARP violations and 230 GARP violations associated with the price alone, significantly 
more than for any other budget. ${ }^{9}$ Notice that the distribution of WARP violations reaches its mode at 0.4 and then declines at high dictator prices. There are no more than approximately 60 WARP violations and no less than 15 WARP violations for all other prices. As expected, there are more GARP violations than WARP violations. The qualitative characteristics for GARP are similar to those for WARP.

\subsection{Efficiency of Choices}

Figure 4.3 shows the severity of the revealed preference violations in the choice data by displaying the distribution of Afriat's CCEI for the 109 subjects who have at least one WARP violation. Recall that some WARP violations may occur along the same budget line. In this case, an $\epsilon$-perturbation to the budget is required to eliminate this violation. Subjects that have only violations of this type have CCEI denoted $1^{*}$. In the figure, the blue bars represent the distribution of the index for our data, and the red bars represent CCEI for the 18 subjects who had violations in Andreoni and Miller (2002), for comparison.

The two distributions are quite different. Most subjects (80\%) in Andreoni and Miller (2002) had a CCEI of $1^{*}$, whereas in our experiment this proportion is only $15 \%$ of subjects. Overall, the cost efficiency is much lower in our data. Based on the $95 \%$ severity threshold for the Afriat's CCEI (Varian, 1991; Andreoni and Miller, 2002), "severe" GARP violations are committed by 56 subjects in our data $(51.4 \%$ of all subjects with GARP violations or $36 \%$ of all subjects in the experiment). In comparison, in Andreoni and Miller (2002) out of 18 subjects only four had the CCEI below $1^{*}$, and in turn three of whom had the CCEI below $95 \%$. Finally, the range of CCEI in our experiment is also wider compared to Andreoni and Miller (2002). The lowest CCEI in our data is around 0.2, suggesting that some of our

\footnotetext{
9 The reason for this large number of violations for this budget is that this budget crosses many other budgets in the neighborhood of average choices, thus presenting a maximal opportunity to observe violations (refer back to Figure 3). Notice, for example, that budget 20 crosses nearly as many budgets, but not in the neighborhood of the average choice as often. This notion of the power of the experimental design to test for WARP and GARP is treated nicely in Andreoni et al (2013).
} 
Figure 6: Distribution of Critical Cost Efficiency Index

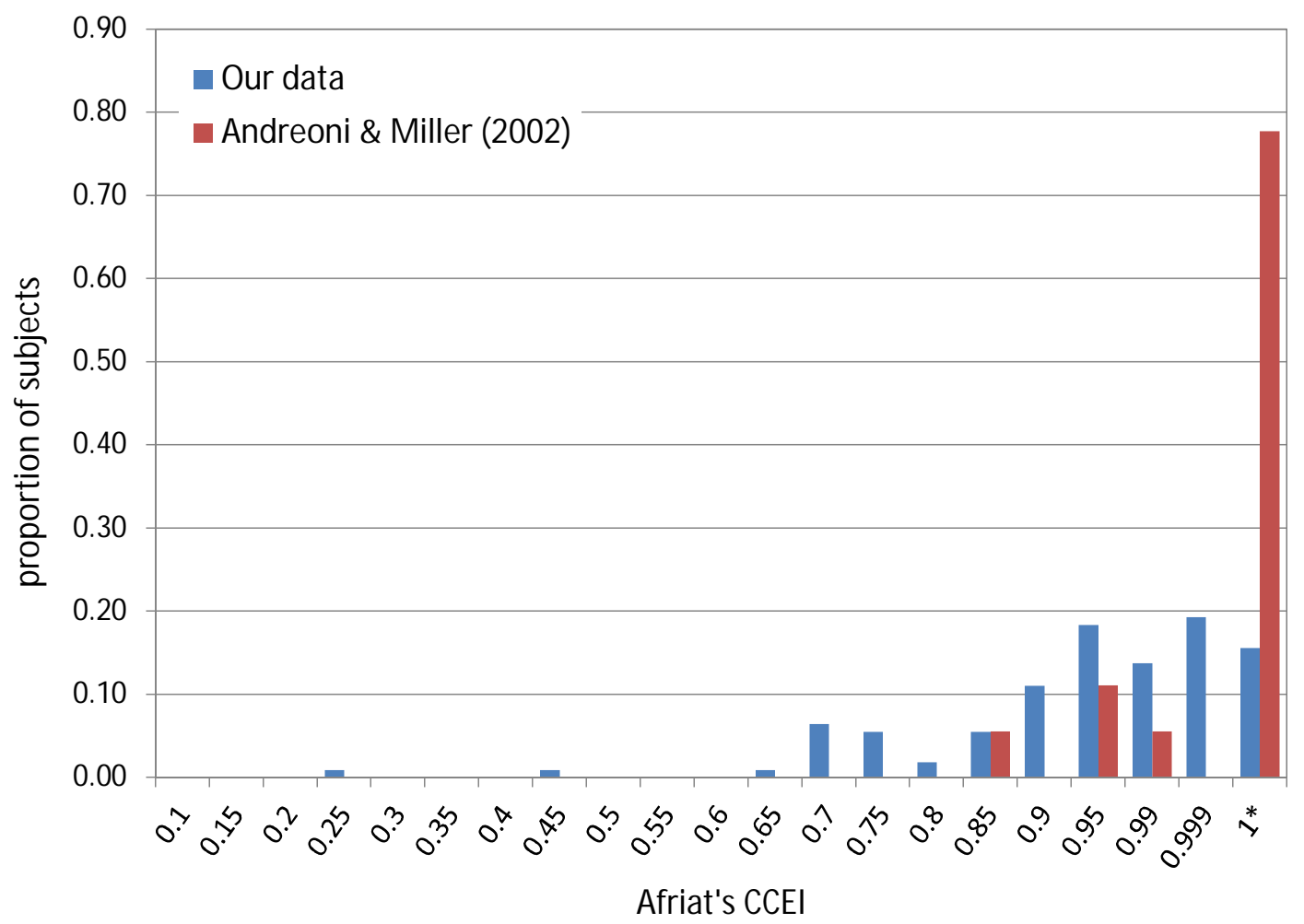

subjects "waste" as much as $80 \%$ of their budgets. For comparison, in Andreoni and Miller (2002) the lowest CCEI was $0.83 .^{10}$

\subsection{Interpreting the Choices}

Figure 7 presents average choices in terms of the share of budget allocated to dictator as a function of dictator price. The choices are presented separately for subjects without violations (white circles) and subjects with violations (grey and black circles). For subjects with

\footnotetext{
10 The distribution of the CCEI computed for 100,000 random subjects was significantly different from that of the actual subjects, which suggests that the actual choices were not random.
} 
Figure 7: Average Choices and WARP violations, by relative price

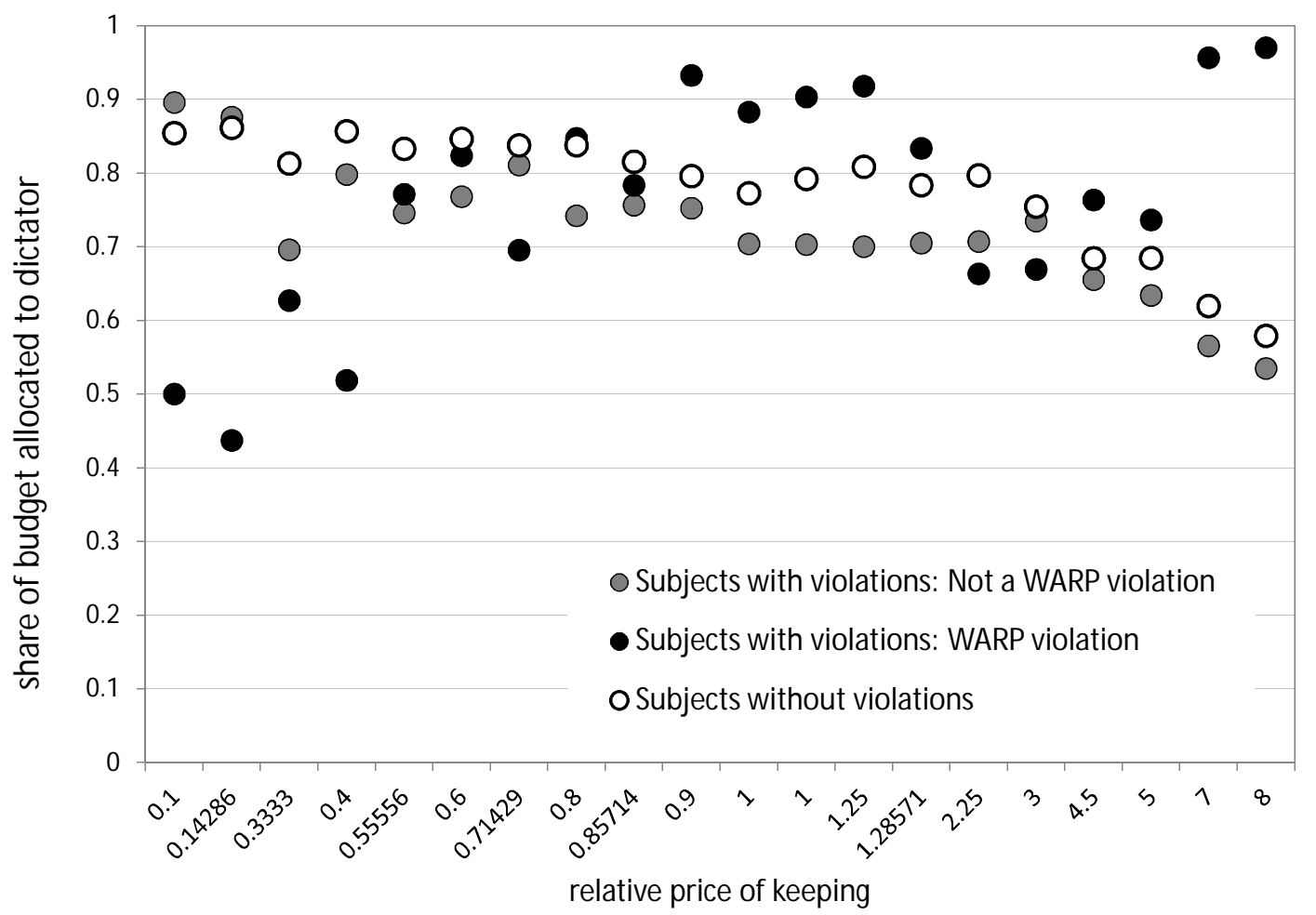

violations, choices are marked as grey circles if they were not WARP violations and as black circles if they were. As before, the $x$-axis refers to budgets, sorted by the relative price and labeled accordingly. The figure reveals a systematic relationship between choices with and without violations and prices.

Figure 7 shows that as the dictator price increases subjects without WARP violations tend to allocate a smaller share to themselves, which is not surprising. A similar downwardsloping pattern is also observed for subjects with WARP violations in the experiment but only for choices that were not involved in a WARP violation. The pattern of decisions associated with a WARP violation is very different: low (high) dictator prices are associated 
with low (high) budget shares kept. In other words, the relationship between the dictator price and the proportion allocated to the dictator is upward-sloping. It is possible that subjects were treating high prices as lower and the low prices as higher than they actually were.

Note that the growing budget share as price goes up is not by itself counterintuitive. Such a pattern would be observed if a dictator consistently allocates relatively similar amounts of money to herself and to the recipient at any price. Decisions like this would indicate that a subject has a modified version of the Leontief utility function given that we can represent this subject's choices with a utility function. In our case, however, a subject with violations followed this strategy of similar allocations only at extreme relative prices and adopted a different strategy at less extreme prices.

The figure, thus, presents preliminary evidence that as a function of price, decisions that violate WARP may be systematically different than decisions that do not violate WARP. To frame these types of violations, the existing literature focuses exclusively on wasted budgets, but does not consider prices. In the next section we introduce a new way to characterize the relationship between prices and violations of WARP.

\subsection{Efficiency of Choices with ICPA}

Given evidence of the potentially systematic relationship between WARP violations and prices presented in Figure 7, it seems natural to explore a re-interpretation of revealed preference violations in the dictator game through the lens of prices. The algorithm to calculate the ICPA-augmented CCEI presented in Section 2.2.2 is designed exactly for this purpose, and we now apply it to budgets at which WARP violations occurred. Note that the proposed algorithm cannot be applied to situations where the two choices constituting a violation already lie on the same budget line. In cases like this, an $\epsilon$-correction is sufficient to eliminate the violation. Out of 109 subjects with WARP violations in our data, 92 subjects 
have violations to which our algorithm can be applied (in total, 263 violations).

In order to separate budget wasting from price misinterpretation, we computed the ICPAadjusted CCEI for the 92 subjects with "correctable" violations. Note that the CCEI for the remaining 17 subjects stays equal $1^{*}$. The resulting distribution of the ICPA-augmented CCEI is presented on a histogram in Figure 8. The red bars show the distribution of the original CCEI (same data as on Figure 4.3), and the blue bars show the distribution for the ICPA-augmented CCEI.

These two distributions are obviously substantially different, with a major shift into the mode of an index of $1^{*}$, suggesting that for the majority of subjects, a minimal price adjustment is enough to eliminate all violations. Without the ICPA, $33 \%$ of subjects have the CCEI of less than the critical level of $95 \%$. The distribution of the CCEI is uniform for those with the index of at least $95 \%$. With the ICPA, $81 \%$ of the subjects have no remaining violations to correct by wasting budgets, and $16.6 \%$ of subjects have the CCEI below the critical level of $95 \%$, most of which at 0.9 . Note the similarity between the CCEI distribution in Andreoni and Miller (2002) and the ICPA-augmented CCEI in our data.

\subsection{Analysis of weighted prices}

To determine the set of prices that renders the choice data rationalizable if leaving budget wasting aside, we apply the iterative ICPA algorithm as described in section 2.2.3. In our data, it took eight iterations to eliminate all violations with the iterative ICPA algorithm. The resulting set of prices was not substantially different from the set of prices used to calculate the ICPA-augmented CCEI.

How do these income-compensated prices, to which we now refer as weighted prices, relate to the actual prices faced by the dictators? Figure 9 presents a scatter plot of the weighted prices against the original values of the dictator's own price. To improve the readability of the graph and to analyze weighted prices when actual prices are favorable to dictator versus 
Figure 8: Distribution of CCEI with and without ICPA

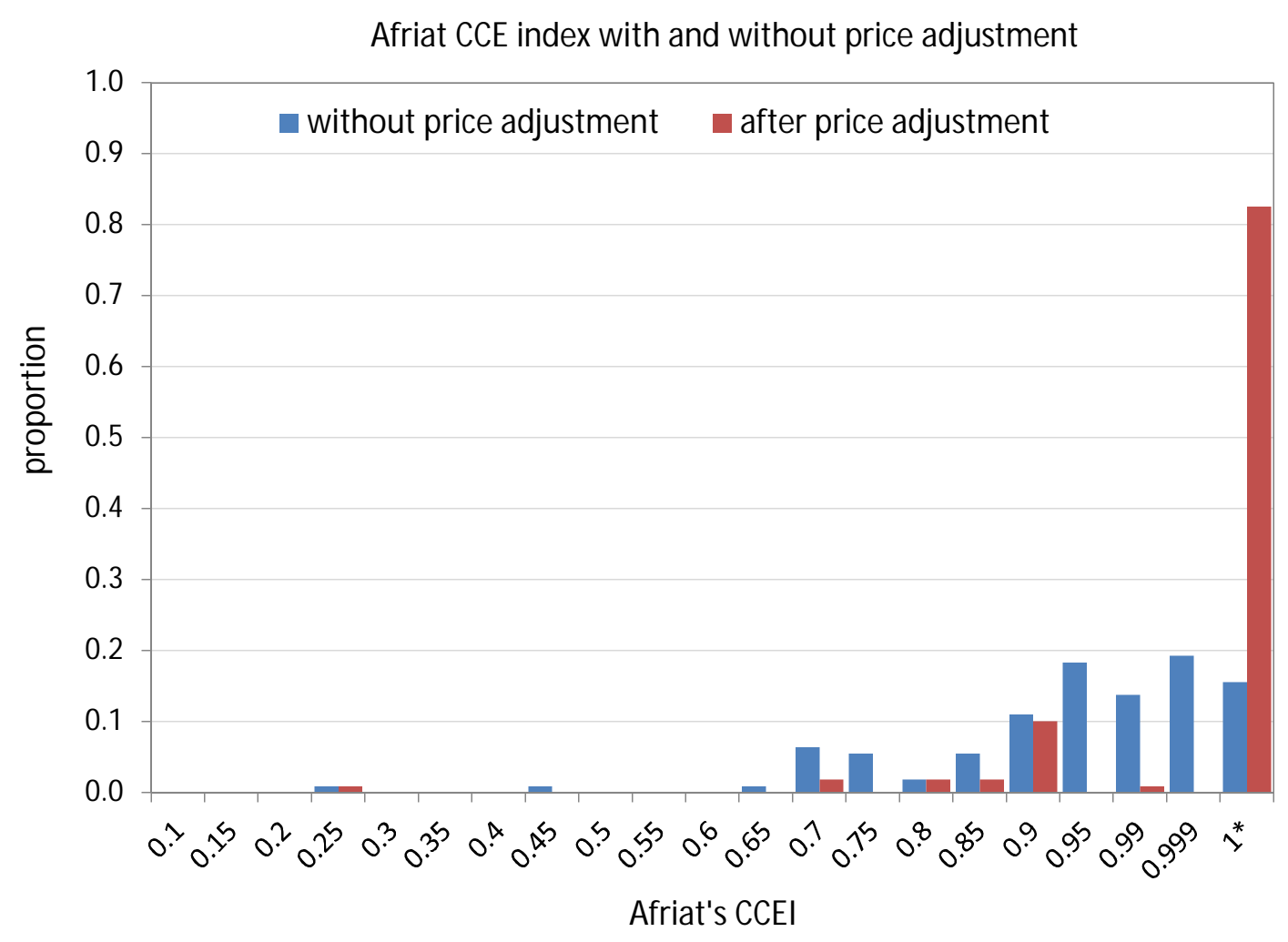


when favorable to recipient, we re-scale both the original and the weighted prices as follows:

$$
p_{\text {scale }}= \begin{cases}p / 2 & \text { if } p \leq 1 \\ 1-1 /(2 p) & \text { if } p>1\end{cases}
$$

The rescaling of the prices gives the same spacing along the horizontal axis to dictator prices between 0 and 1 as it does to dictator prices between 1 and 10. Without the rescaling, low prices are confined to the interval between 0 and 1, whereas high prices range from 1 to 10 , leaving 9 times the space for high prices as for low prices. The rescaling thus gives the same space along the axis for cheap dictator prices as for expensive prices, reflecting analogous prices equal distances from the rescaled price of 0.5 , which is itself equivalent to a relative price of keeping of 1 . For example, the prices $1 / 10$ and 10 are equally spaced from 0 and 1 on the horizontal axis, respectively. Thus, prices from 0 to 1 are equally spaced in the interval between 0 and 0.5 , and prices from 1 to 10 are equally spaced in the interval between 0.5 and 1. Looking ahead at Figure 9, both axes in the figure use rescaled prices. Table 1 maps rescaled prices to actual prices in the figure.

In Figure 9, the weighted prices appear to be mostly above the 45-degree line for low prices (below 0.3 on the rescaled axis), and then mostly below the 45-degree line for higher prices. This is visually clear upon inspection of the weighted prices at the price indices between 0.2 and 0.6. At the index of 0.2 , all of the weighted prices are above the 45-degree line, indicating subjects behaving as if the low price of keeping were actually higher. At the index of 0.3 , most weighted prices are above the 45 -degree line, but not all. At 0.4 , most but not all weighted prices shift below the 45-degree line. At 0.6, all weighted prices shift below the 45-degree line, indicating that many subjects behave as if the price of keeping were lower than it actually is, and continue to do so for all higher prices.

The weighted prices visually appear to trace a concave shape below the scaled price of 0.3 and a convex shape above it. This so-called regressive, $S$-shaped, and asymmetric pattern is also found in the probability weighting function in non-expected utility (Prelec, 1998). In 
Figure 9: Weighted vs. actual price

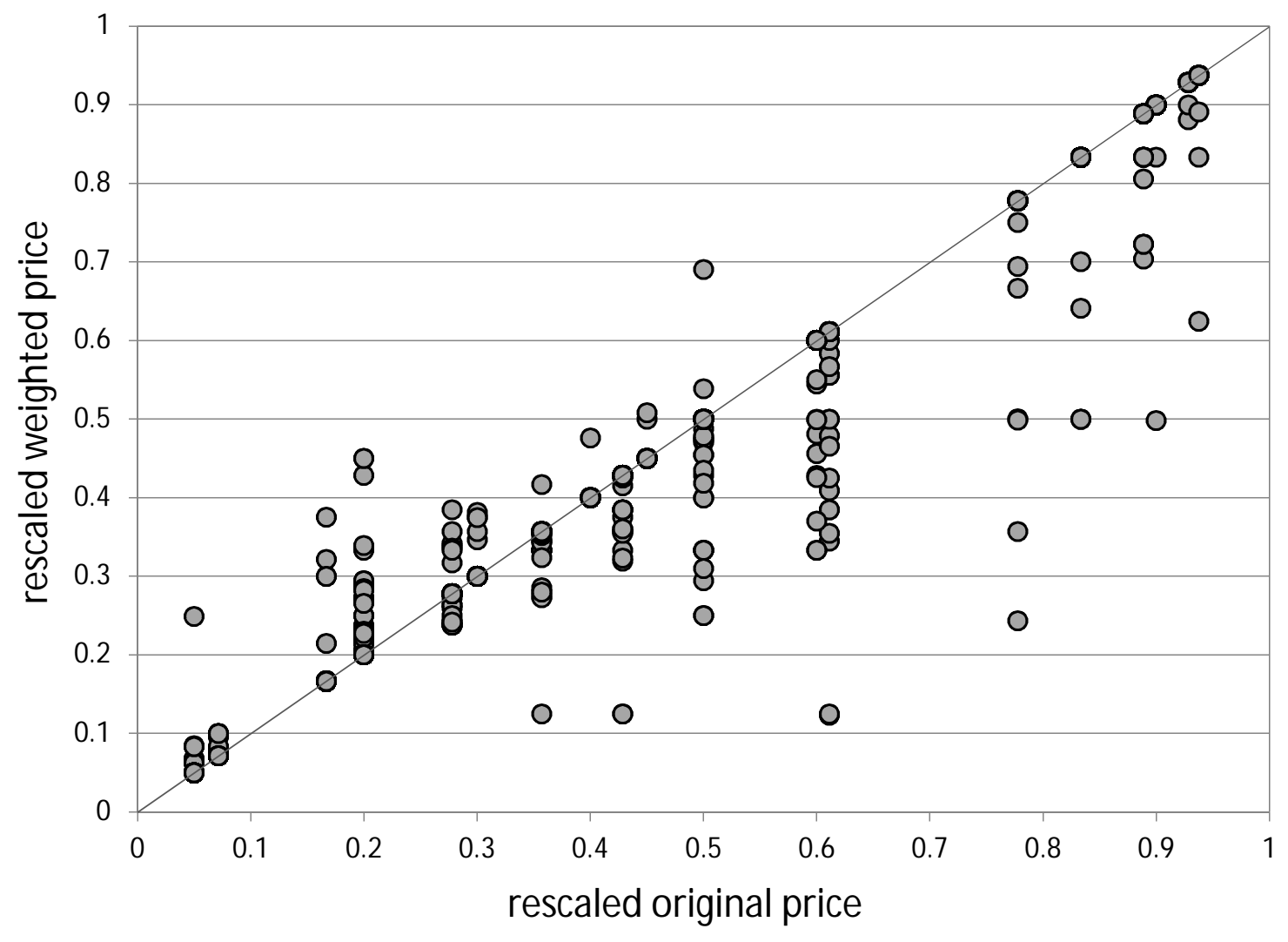


Table 1: Mapping Rescaled Prices to Actual Prices

\begin{tabular}{cc} 
Rescaled Price & Actual Price \\
\hline 0.1 & 0.2 \\
0.2 & 0.3 \\
0.3 & 0.6 \\
0.4 & 0.8 \\
0.5 & 1.0 \\
0.6 & $\frac{1}{0.8}$ \\
0.7 & $\frac{1}{0.6}$ \\
0.8 & $\frac{1}{0.4}$ \\
0.9 & $\frac{1}{0.2}$ \\
\hline
\end{tabular}

the next section we apply this function to the weighted prices in Figure 9.

\subsection{The Price Model}

To better describe the weighted prices (i.e., the prices that result from our iterative ICPA algorithm), we fit a model to them in this section. This exercise simply fits a curve through weighted prices while, for now, ignoring the prices that did not have to be adjusted to eliminate violations of GARP. Our price model is an adaptation of the non-linear probability weighting function of Prelec (1998), which was axiomatically derived to fit the empirical choices over lotteries described in Kahneman and Tversky (1979). This function has the property of being $S$-shaped that is evident in Figure 9.

The functional form of the weighting function is

$$
w p_{\text {scale }}=\exp \left(-\beta\left(-\ln \left(p_{\text {scale }}\right)\right)^{\alpha}\right)
$$

where, in our application, $p_{\text {scale }}$ is the rescaled actual dictator price, and $\alpha$ and $\beta$ are parameters of the function. The two parameters have an intuitive behavioral interpretation, 
much as they do when the function is used as a probability weighting function (Abdellaoui et al., 2011). First, $\alpha$ controls the degree to which the function is $S$-shaped, and together with $\beta$ determines the "price insensitivity" of the dictator. Intuitively, wherever the function crosses the 45-degree line, decision making is as if extreme prices are being pushed toward this fixed point. Second, $\beta$ controls the convexity of the function, which we interpret as "own-price discounting". The more the function is convex below the 45-degree line, the more the dictator is underweighing, or discounting, her own price.

\subsection{Fitting the Price Function to Aggregate Data}

We first fit the function to the weighted prices that rationalize decision-making in our data, shown in Figure 9. As a first pass at describing the data conditional on violations of GARP, we fit only the data with violations. Later, we run subject-by-subject regressions on all choice data for subjects with violations, for a complete model of weighted prices. Fitting the data requires a transformation of both sets of prices, as the domain of the function is restricted to a $[0,1]$ interval, which makes our price rescaling convenient.

We fit the function to the data as follows. First, we scale both the original and weighted prices to fall into a $[0,1]$ interval as described above. Next, we transform both sets of scaled prices in order to estimate Prelec's equation using the OLS:

$$
\begin{aligned}
& y=\ln \left(-\ln \left(w p_{\text {scale }}\right)\right) \\
& x=\ln \left(-\ln \left(p_{\text {scale }}\right)\right)
\end{aligned}
$$

where $p_{\text {scale }}$ and $w p_{\text {scale }}$ are scaled original and scaled weighted prices, respectively. The interpretation of the regression parameters is straightforward. The coefficient at $x$ is $\alpha$ (the price insensitivity parameter) and the constant is $\ln (\beta)$ (own-price discounting). ${ }^{11}$ The point estimate of $\alpha$ is 0.6357 , which indicates an $S$-shaped function that defines price insensitivity.

\footnotetext{
11 Since the same budget could be involved in more than one violation, the 263 violation instances in our data are related to 225 unique budgets. Observations were assumed i.i.d.
} 
Figure 10: Fitted scaled prices

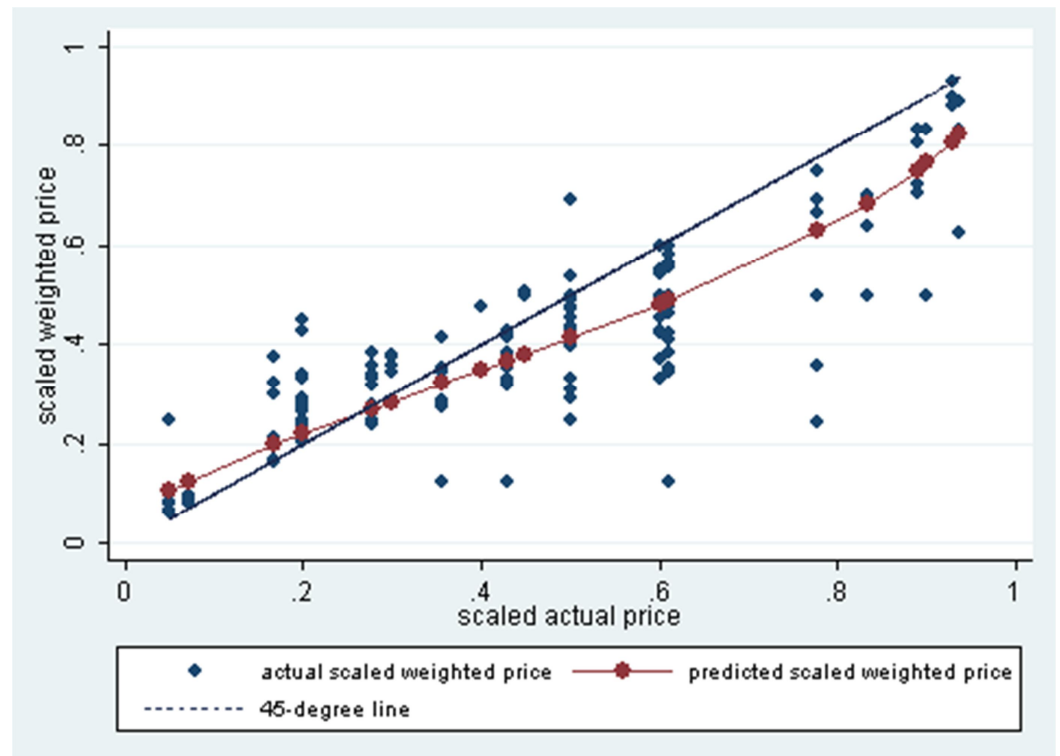

The estimate of $\beta$ is 1.115 indicating a convex function that defines own-price discounting. Thus, the description of the weighted prices fits that of price insensitivity as well as price discounting. Note that estimates of 1 for both parameters would imply a price function coinciding with the 45-degree line, suggesting that the weighted price is identical to the actual price. Our estimates for the aggregate data are statistically significantly different from 1 for both parameters.

Figure 10 displays the rescaled weighted prices on the vertical axis against the rescaled actual prices on the horizontal axis as before, but now also traces the function implied by the parameter estimates. It is easy to see that the rescaled weighted price of keeping is above the 45-degree line at low prices, and below the 45-degree line at high prices, and the rescaled weighted prices are being "pushed toward" the fixed point at a value just under 0.3 indicating price insensitivity.

We now turn to the central result of our paper, which we present with individual subject 
regressions. To see the heterogeneity of parameter values (and hence different types of price behavior) in our data, we next estimated a weighted price function for each of the 92 subjects with WARP violations, where we use all 20 observations per subject, including prices that do not have to be adjusted. Figure 11 presents the individual and joint distributions of the parameters estimates. The top half of the figure shows histograms of the individual parameter distributions. The histograms confirm the aggregate results: the price insensitivity parameter, $\alpha$, has a mode at 1 but is centered at values less than one, indicating a bias towards price insensitivity. The price discounting parameter, $\beta$, is centered at one, indicating roughly equal amounts of own-price discounting and the opposite behavior of overweighing the dictator price which we will call own-price inflating. The bottom half of the figure shows a scatter plot of the joint distribution of the two parameters. It shows a positive association between $\alpha$ and $\beta$. In other words, higher degrees of price insensitivity are correlated with higher degrees of price discounting.

Individual regressions confirm the richness of the heterogeneity implied by the histograms of individual regression parameter estimates. Figure 12 shows four different functions estimated from the decisions of four subjects. The estimates show a range of price discounting, seen most clearly in the convexity of the estimated function in the top-left figure (Subject 21 , but present in all four cases. The figure also indicates the heterogeneity of price insensitivity: the Subject 21 in the top-left of the figure shows none, whereas each of the other three subjects show a fixed point at different prices. The weighted prices of subject 63 (top-right) are pushed symmetrically in toward the relative price of 1: making this subject's choices rationalizable requires adjusting prices at each extreme, but the point at which the weighted price and actual price are the same is almost exactly where the relative price of the two allocations are equal. Subjects 144 and 111 in the bottom half of the figure have their fixed points at low and high prices, respectively.

It is important to note that the heterogeneity indicated in these graphs implies distinct 
decision making. Subject 21 discounts the dictator's price across the entire range of prices, with the effect most pronounced in the center of the price range. At a relative price of 1, rendering the data rationalizable requires interpreting that this price as less than 1 . This dictator behaves as though all prices she faces are lower than they actually are, discounting relatively even prices at a higher rate than extreme prices.

The remaining three subjects exhibit different types of insensitivity to extreme prices. It is easy to see why this is insensitivity: at the low end of prices weighted prices are higher than the actual prices, and the opposite is true at the high end. Thus, the weighted prices reduce the allocative effect of the extremes of the actual prices. The fixed point, that is, the point at which the true price is identical to the weighted price, occurs in three different qualitative locations in the dictator price interval (low, medium, and high prices). This shows that subjects differ not only in the magnitude of price insensitivity, but also in the location toward which the extreme prices are being pushed.

Note that inflating low prices makes them less desirable for the dictator than they really are, whereas deflating high prices increases their favorability to the dictator. When the fixed point is not at the price of 1 , then subjects either inflate all favorable prices along with the lowest unfavorable prices when the fixed point is less than 1 (e.g., subject 144), or they deflate all unfavorable prices and the highest favorable prices when the fixed point is greater than 1 (e.g., subject 111). These are distinctly different types of price weighting that seem to imply different subjective behavior toward dictator game prices. 


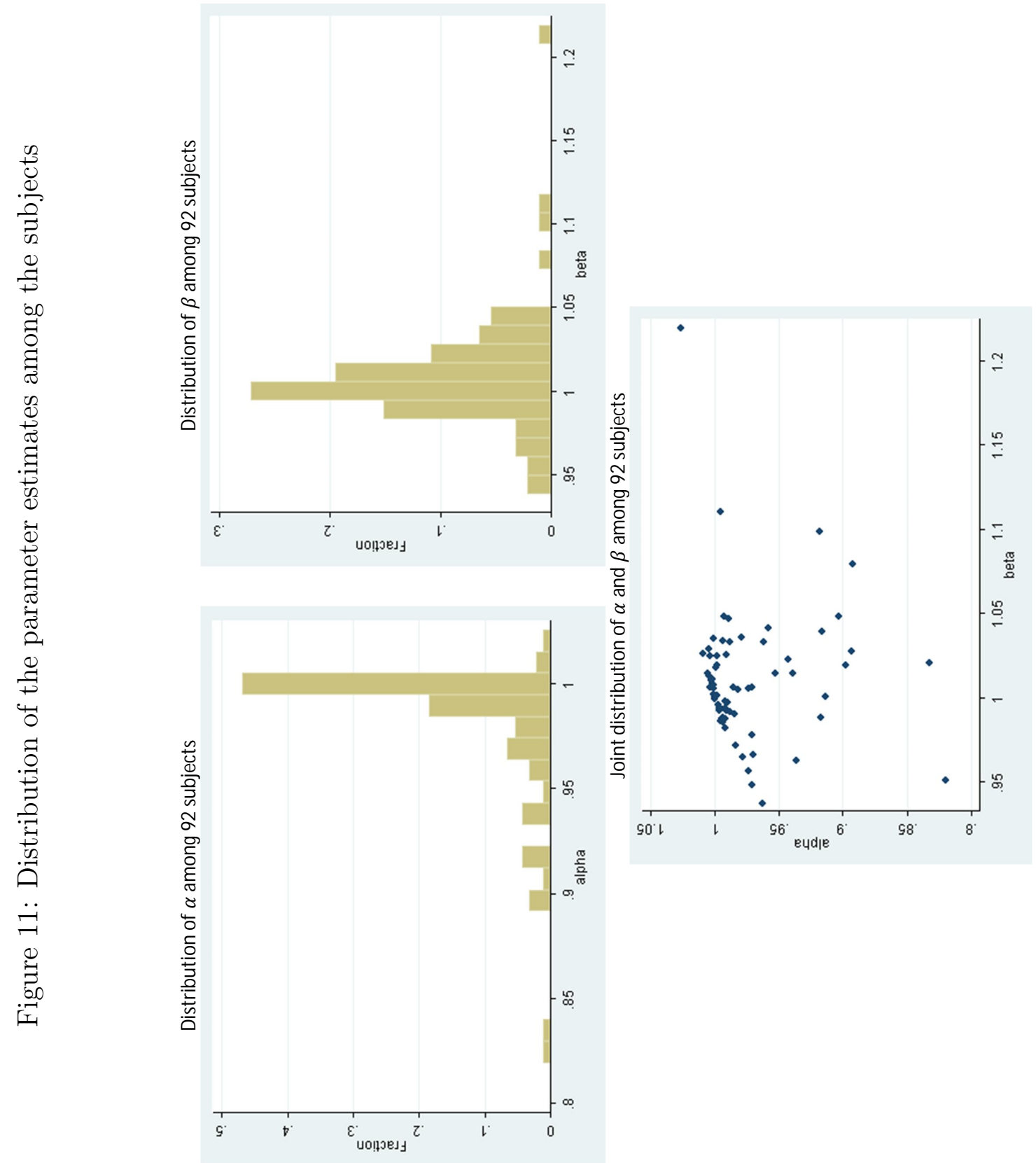




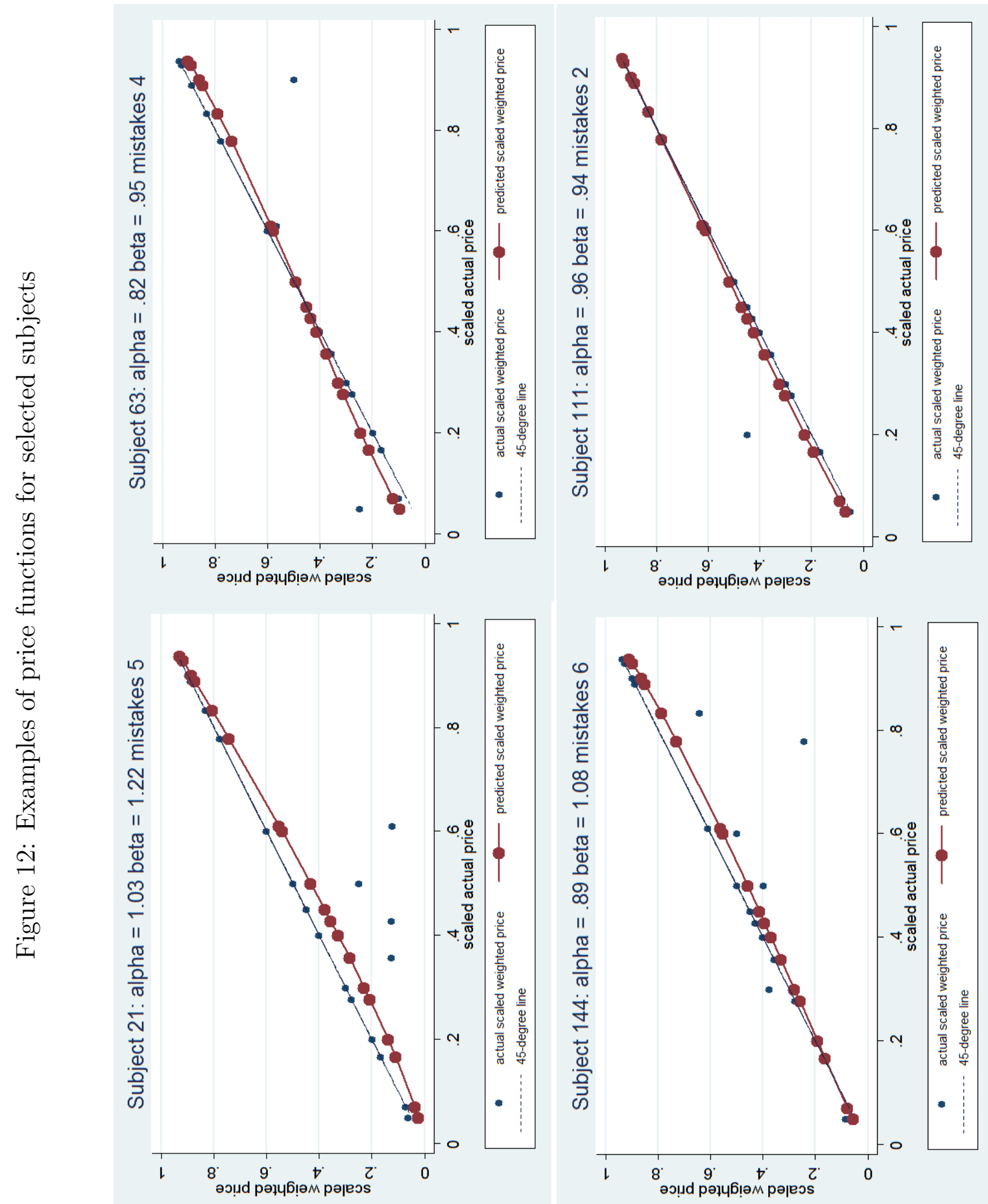




\section{Conclusion}

In this paper we took a new look at non-rationalizable decision making in the dictator game. By varying budget constraints so that relative prices of allocating are sometimes extreme, we find significantly more violations of demand theory than past studies have indicated. We also found more extreme violations in the sense of greater budget wasting, indicating a need for a re-interpretation of the results.

We proposed an algorithm of income-compensated price adjustments that removed the violations and fitted a price-weighting function to the prices that rationalize violations. We showed that applying that standard measure of the severity of violations, the CCEI, to weighted prices, helps explain why our data are different than in past studies, and confirms that the variation in prices drives the results.

We demonstrated the behavioral interpretability of the price weighting function on our data. The price insensitivity parameter, $\alpha$, has a mode at 1 but is centered at values less than one, indicating much price insensitivity. The own-price discounting parameter, $\beta$, is concentrated at 1, indicating equal amounts of own-price discounting and own-price inflation. We also found a positive association between price insensitivity and own-price discounting.

Our results are analogous to long-standing results in non-expected utility theory. Dictators behave as if they are insensitive to extreme prices, and many discount their own prices. These results suggest that decision making in domains where social and altruistic preferences operate can be reinterpreted to some extent. They suggest that while decision making largely conforms to demand theory at even prices, the price itself, and not just the preference, has a subjective effect on allocation choices. Our results suggest that atheoretical reactions to prices, and not just (social) preferences, should be taken into account in allocation decisions in games. 


\section{References}

Abdellaoui, M., A. Baillon, L. Placido, and P. Wakker (2011). "The Rich Domain of Uncertainty: Source Functions and Their Experimental Implementation", American Economic Review 101(2):695-723.

Afriat, S. (1967). "The Construction of Utility Functions From Expenditure Data", International Economic Review 8(1):67-77.

Afriat, S. (1972). "Efficiency Estimation of Production Functions", International Economic Review 13(3):568-598.

Andreoni, J., B. Gillen, and W. Harbaugh (2013). "The Power of Revealed Preference Tests: Ex-Post Evaluation of Experimental Design". Working Paper, March 8, 2013.

Andreoni, J. and J. Miller (2002). "Giving According to GARP: An Experimental Test of the Consistency of Preferences for Altruism". Econometrica 70(2):737-753.

Battalio, R, J. Kagel, H. Rachlin, and L. Green (1981). "Commodity-Choice Behavior with Pigeons as Subjects", Journal of Political Economy 89(1):67-91.

Battalio, R., J. Kagel, R. Winkler, E. Fisher, R. Basmann, and L. Krasner (1973). "A Test of Consumer Demand Theory Using Observations of Individual Consumer Purchases", Economic Inquiry 11(4):411-428.

Burghart, D., P. Glimcher, and S. Lazzaro (2013). "An Expected Utility Maximizer Walks Into a Bar...", Journal of Risk and Uncertainty, 46(3): 215-246.

Cox, J. (1997). "On Testing the Utility Hypothesis", The Economic Journal 107:1054-1078.

Fevrier, P. and M. Visser (2004). "A Study of Consumer Behavior Using Laboratory Data", Experimental Economics 7:93-114.

Fischbacher, U. (2007). "z-Tree: Zurich Toolbox for Ready-made Economic Experiments", Experimental Economics 10(2): 171-178.

Fisman, R., S. Kariv, and D. Markovits (2007). "Individual Preferences for Giving". American Economic Review 97(5):1858-1876.

Forsythe, R., J. Horowitz, N.E. Savin, and M. Sefton (1994) "Fairness in Simple Bargaining Experiments", Games and Economic Behavior 6(3):347-369.

Harbaugh, W., K. Krause, and T. Berry (2001). "GARP for Kids: On the Development of Rational Choice Behavior", American Economic Review 91(5):1539-1545.

Houthakker, H. (1950). "Revealed Preference and the Utility Function", Economica (New Series) 17(66):159-174. 
Mattei, A. (2000). "Full-Scale Real Tests of Consumer Behavior Using Experimental Data", Journal of Economic Behavior and Organization 43(4):487-497.

Samuelson, P. (1938). "A Note on the Pure Theory of Consumer's Behavior", Economica (New Series) 5(17):61-71.

Sippel, R. (1997). "An Experiment on the Pure Theory of Consumer's Behaviour", The Economic Journal 107(444):1431-1444.

Varian, H. (1982). "The Nonparametric Approach to Demand Analysis", Econometrica $50(4): 945-973$.

Varian, H. (1983). "Non-Parametric Tests of Consumer Behavior", Review of Economic Studies 50(1):99-110.

Varian, H. (1990). "Goodness of Fit in Optimizing Models", Journal of Econometrics 46(1-2):125-140.

Varian, H. (1991). "Goodness of Fit for Revealed Preference Tests", University of Michigan CREST Working Paper 13. 